\title{
Differentiation between infectious spondylodiscitis versus inflammatory or degenerative spinal changes: How can magnetic resonance imaging help the clinician?
}

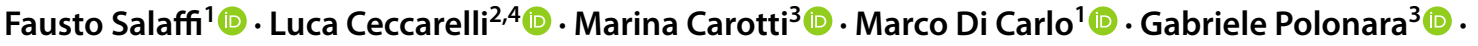 \\ Giancarlo Facchini ${ }^{4}\left(\mathbb{D} \cdot\right.$ Rita Golfieri $^{2} \odot \cdot$ Andrea Giovagnoni $^{3}(\mathbb{D}$
}

Received: 22 August 2020 / Accepted: 14 March 2021 / Published online: 2 April 2021

(C) The Author(s) 2021

\begin{abstract}
Spondylodiscitis is a complex disease whose diagnosis and management are still challenging. The differentiation between infectious and non-infectious aetiology is mandatory to avoid delays in the treatment of life-threatening infectious conditions. Imaging methods, in particular magnetic resonance imaging (MRI), play a key role in differential diagnosis. MRI provides detailed anatomical information, especially regarding the epidural space and spinal cord, and may allow differential diagnosis by assessing the characteristics of certain infectious and inflammatory/degenerative lesions. In this article, we provide an overview of the radiological characteristics and differentiating features of non-infectious inflammatory spinal disorders and infectious spondylodiscitis, focussing on MRI results and presenting relevant clinical and pathological features that help early diagnosis.
\end{abstract}

Keywords Spondylodiscitis $\cdot$ Magnetic resonance imaging $\cdot$ Vertebral infection $\cdot$ Spondyloarthritides

\section{Introduction}

Spondylodiscitis can be divided into two major macrocategories, namely non-infectious inflammatory spinal disorders and infectious diseases [1]. The definition of spondylodiscitis in the strict sense applies to infectious diseases; however, there are several non-infectious conditions that can mimic the presence of an infectious vertebral disease. The distinction between inflammatory/degenerative versus infectious

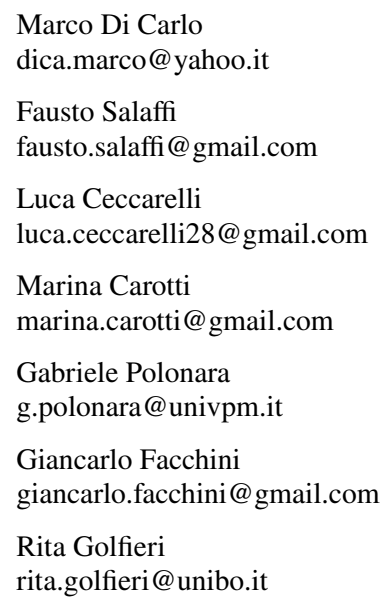

pathology has a huge prognostic impact. The correct diagnosis of infection basically requires two main criteria: the presence of characteristic lesions in the spine and the isolation of the pathogen from blood or infected site. Therefore, radiological evaluation is important both for the diagnosis of spondylodiscitis and for further planning and monitoring of treatment.

Magnetic resonance imaging (MRI) is considered the imaging modality of choice for the detection and evaluation

Andrea Giovagnoni

a.giovagnoni@univpm.it

1 Clinica Reumatologica, Ospedale "Carlo Urbani", Dipartimento Di Scienze Cliniche E Molecolari, Università Politecnica Delle Marche, Via Aldo Moro, 25, 60035 Jesi, Ancona, Italy

2 Unità di Radiologia, Dipartimento di Medicina Specialistica, Diagnostica E Sperimentale, Ospedale Sant'Orsola, Università Di Bologna, Via Albertoni 15, 40138 Bologna, Italy

3 Dipartimento di Scienze Radiologiche, Ospedali Riuniti, Università Politecnica Delle Marche, Ancona, Italia

4 Radiologia Diagnostica ed Interventistica, IRCCS Istituto Ortopedico Rizzoli, Via GC Pupilli 1, 40136 Bologna, Italia 
of spondylodiscitis, with a sensitivity of $96 \%$ and specificity of $92 \%$ in the diagnosis of infectious processes [2].

In this article, an overview of radiological appearances of non-infectious inflammatory spinal column disorders and infectious spondylodiscitis has been provided, focussing on MRI results and presenting relevant clinical and pathological features that help early and differential diagnosis.

\section{Inflammatory disorders of the spine}

A variety of inflammatory non-infectious disorders may involve the spine. Of these, axial spondyloarthritis (axSpA), synovitis-acne-pustulosis-hyperostosis-osteitis (SAPHO) syndrome, active discopathy-related spinal abnormalities (named Modic type 1 lesion), calcific disease or spinal gout are the most commonly encountered causes of spondylodiscitis. Destructive spondyloarthropathies can also be seen in patients with a story of long-term haemodialysis (Table 1).

\section{Axial spondyloarthritis}

Ankylosing spondylitis (AS), psoriatic arthritis, reactive arthritis and enteropathic arthritis are included in the context of axSpA [3]. MRI has radically changed the diagnostic approach of these conditions, to the extent that the latest classification criteria for axSpA, developed by the Assessment of SpondyloArthritis International Society (ASAS), have included MRI of the sacroiliac joints and spine for diagnostic/classification purposes [4]. The recommended approach for spine imaging in patients with axSpA includes T1-weighted sequences to assess the morphology of structures, T2-weighted sequences or short tau inversion recovery (STIR) to detect bone marrow edema (BME), and T1-weighted sequences suppressed with gadolinium to show tissue inflammation (enthesitis and synovitis) [5]. Characteristically, inflammatory lesions of the vertebral spine are present in several areas. Typically, inflammatory lesions of axSpA are found at the angular level (the presence of BME of the anterior vertebral angles is called Romanus lesions), at the central level, in the lateral and posterior spinal segments such as pedicles, costotransverse, costovertebral, and zigoapophyseal joints (Fig. 1) [6]. The lesions may then tend towards erosive evolution in the anterior part of the thoracolumbar vertebral bodies [7] and, subsequently, erosions are associated with sclerotic changes and syndesmophytes which, in long-term disease, tend to fuse. Both active and structural lesions of the spine may be present in a patient simultaneously.

MRI is the only imaging tool capable of visualizing BME [8]. At these anatomical points, BME indicates active inflammation and consequently is highly suggestive of axSpA presence. However, specificity of BME in the diagnosis of axSpA is limited, since BME can be expression of mechanical back pain even in young patients [9]. Changes such as fat infiltration, erosion, or ankylosis indicate structural damage [10]. Romanus lesions are more clearly identified in the sagittal plane and are characterized by the presence of triangular-shaped BME at the corners of the vertebral endplates, with low signal on T1-weighted images and high signal on STIR and T2-fat suppressed sequences (Fig. 2). A spinal 'positive MRI' is defined by Outcome Measures in Rheumatology Clinical Trials (OMERACT) and the ASAS group when at least three inflammatory lesions of the anterior and/ or posterior corners (anterior or posterior spondylitis) or fat deposits at the vertebral corners are present [11].

Table 1 Inflammatory non-infectious disorders of the spine and infectious aetiology of pyogenic spondylodiscitis

\begin{tabular}{ll}
\hline Inflammatory non-infectious disorders of the spine & Infectious spondylodiscitis \\
\hline Spondyloarthritides [axSpA]* & Pyogenic vertebral osteomyelitis \\
Synovitis-acne-pustulosis-hyperostosis-osteitis [SAPHO] & Gram-positive aerobic cocci \\
Modic changes type-1 syndrome & Staphylococcus aureus, Staphylococcus epidermidis, Haemophilus influenzae, \\
Acute symptomatic calcific discitis & Streptococcus pyogenes, Enterococcus spp., other streptococci \\
Spinal gout & Gram-negative aerobic bacilli \\
Destructive spondyloarthropathy of haemodialysis & Escherichia coli, Proteus spp., Pseudomonas aeruginosa, Klebsiella pneumoniae, \\
& Enterobacter spp., Salmonella \\
& Infectious granulomatous diseases \\
& Tuberculous spondylodiscitis \\
& Brucella spondylodiscitis \\
& Fungal infection \\
& Candida spp., Aspergillus spp., Cryptococcus, Coccidioides immitis, Blastomyces \\
dermatitidis & Parasitic spinal infections \\
& Taenia solium, Schistosoma japonicum, S. mansoni, S. haematobium, Toxoplasma \\
& gondii, Echinococcus granulosus \\
\hline
\end{tabular}

*axSpA comprise ankylosing spondylitis (AS), reactive arthritis, arthritis/spondylitis in inflammatory bowel diseases (IBD), and psoriatic arthritis with axial involvement 


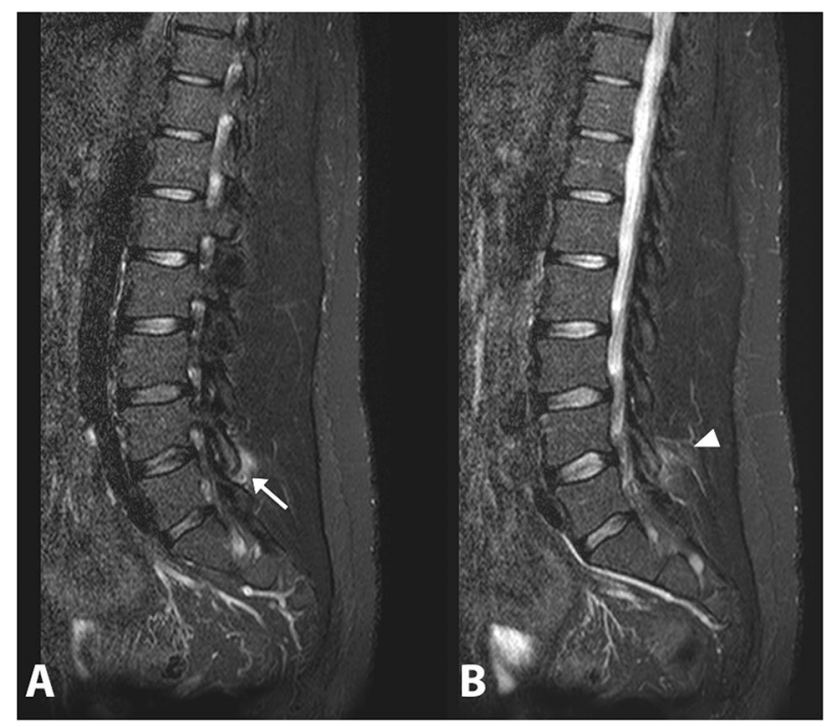

Fig. 1 Sagittal STIR images (a, b) active inflammation of the left facet joint at L4-L5 (arrow). Inflammation of the adjacent soft tissue can also be observed (arrowhead)

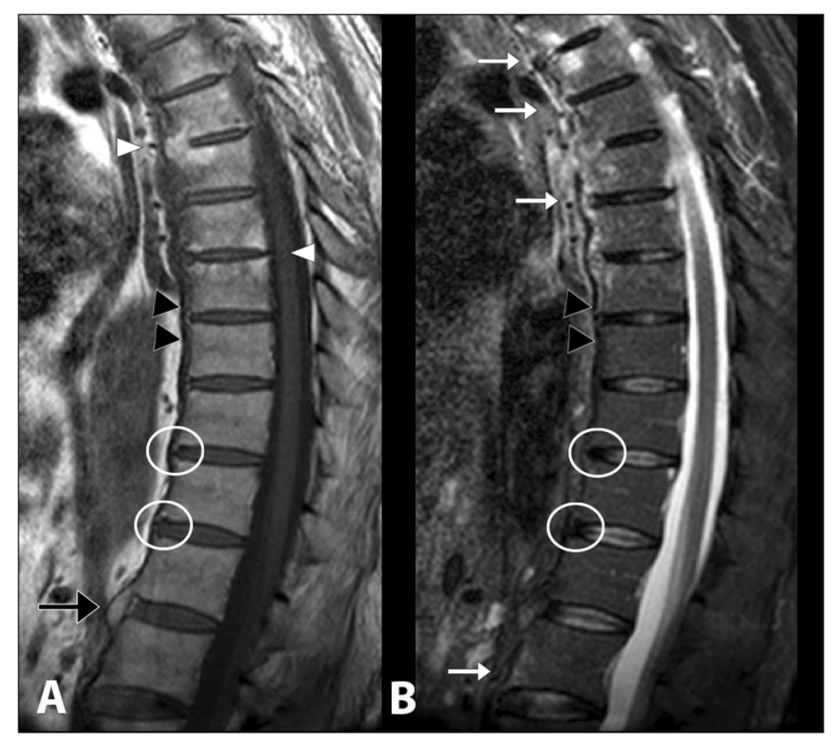

Fig. 2 Sagittal T1-weighted image (a) and sagittal STIR image (b) showing hypointense and hyperintense lesions, respectively, at the anterior edges of vertebral bodies from D3 to D8 and in L1, indicating bone marrow edema (Romanus lesions) (white arrows). The postinflammatory areas of fatty degeneration of the bone marrow are visible at the anterior edges of the opposite vertebral bodies D5/D6 and at the posterior edges of D7 and D8 (white arrowheads). Thickening of the anterior longitudinal ligament (black arrowheads) and multiple syndesmophytes (white circles) can also be detected. Furthermore, in D12-L1 it is possible to observe a bony bridge (black arrow), which could result from the progression of ossification on syndesmophytes

Occasionally, axSpA are accompanied by erosive focal changes in the vertebral terminal plate, defined as
Andersson's lesions. These alterations are difficult to differentiate from the typical results of infectious spondylodiscitis. The incidence of Andersson's lesions is about 8-16\%, commonly occurring in thoracolumbar segments [12]. MRI is fundamental in the differentiation between Andersson's lesions and infectious spondylodiscitis.

In MRI, during the progression of bacterial spondylodiscitis, the disc often becomes a focal point for fluid collection. In axSpA, however, the disc usually retains its regular signal intensity or shows only signs of degeneration. Therefore, in axSpA, variations in signal intensity are likely to be limited within the vertebral body and the vertebral end plate, but not in the disc. Furthermore, perivertebral effusion and intradiscal effusions are rarely seen in discovertebral lesions in axSpA. The high signal intensity on $\mathrm{T} 2$-weighted images observed in Andersson's lesions usually corresponds to granulation tissue, and high-intensity T2 peripheral areas reflect infiltration of tissue and inflammatory cells, not fluid collection (Fig. 3). The lack of intradiscal or perivertebral fluid collection is an important diagnostic sign [13].

\section{Non-bacterial osteitis syndromes}

Synovitis, acne, pustulosis, hyperostosis, and osteitis (SAPHO) syndrome and chronic recurrent multifocal osteomyelitis (CRMO) represent the spectrum of autoinflammatory bone diseases in which non-infectious osteitis is the unifying feature collectively termed non-bacterial osteitis syndrome (NOS). There is a striking overlap of symptoms and comorbidities between CRMO and SAPHO. CRMO may represent the paediatric presentation of SAPHO.

Under the term SAPHO syndrome are included chronic inflammatory disorders that have in common musculoskeletal manifestations characterized by the presence of synovitis, hyperostosis and osteitis, associated with characteristic skin manifestations such as neutrophilic rashes, palmo-plantar pustulosis or acne conglobata. The SAPHO syndrome can affect all ages. The most commonly affected skeletal region of the SAPHO syndrome is the anterior chest wall (ACW), including the sternoclavicular, manubriosternal and costosternal joints. The spine is the second most common site of skeletal involvement, and spinal abnormalities can be documented in up to $50 \%$ of adult patients [14].

Axial inflammatory manifestations can involve multiple sites and combine in different ways [15]. Elementary radiological lesions include angular lesions of the vertebral body, non-specific spondylodiscitis (very similar to infectious forms), osteolytic lesions with varying degrees of collapse of the vertebral body (visible lesions even in childhood), osteosclerosis of one or more vertebral bodies with development of hyperostosis, paravertebral ossification, and sacroiliitis (more common in adulthood) [15]. Angular erosions seen on MRI may suggest enthesitis and are somehow the equivalent 
Fig. 3 Sagittal T1-weighted image (a), sagittal T2-weighted image (b) and sagittal STIR image (c) showing a typical active Andersson lesion at D7/ D8, with subchondral edemaosteitis, discitis and erosions (arrow). Romanus lesions can be observed in the anterior corners of the vertebral bodies at D6, D7 and at L1 and L2 (arrowheads)

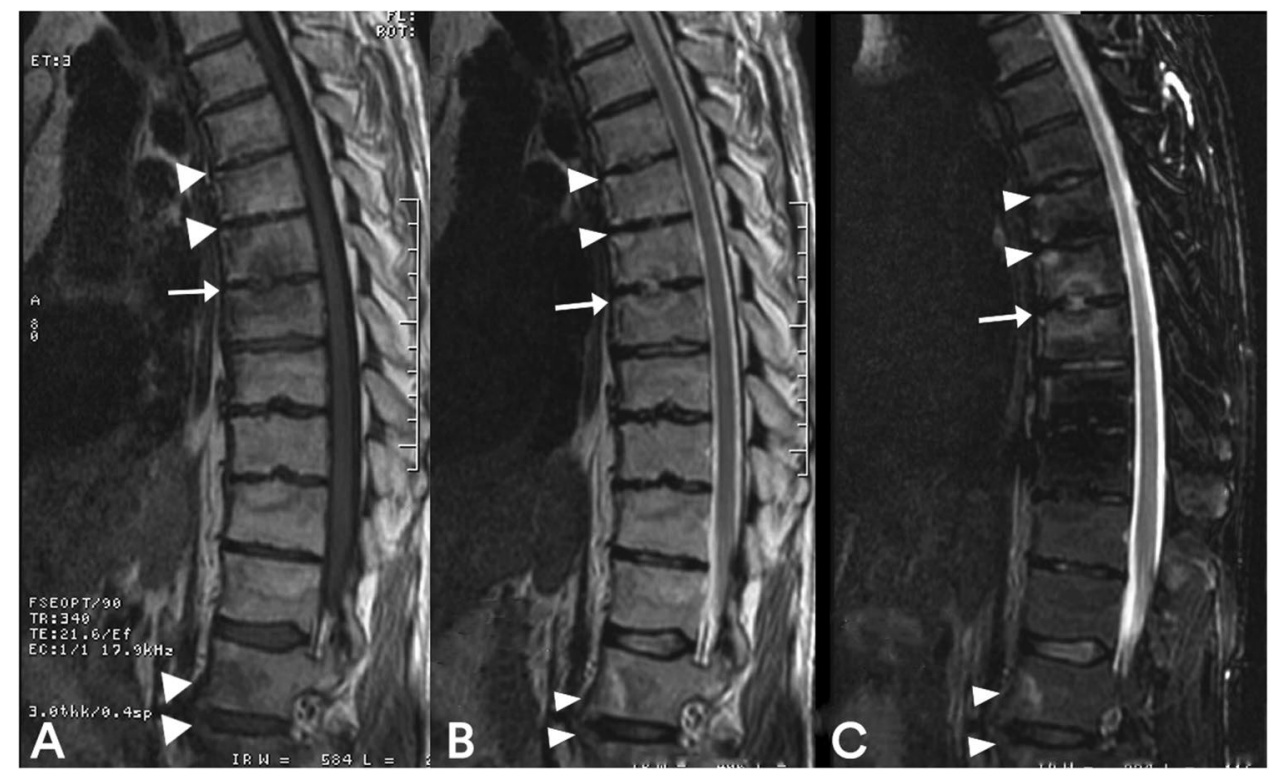

of Romanus' lesion in axSpA. Similar to axSpA, active MRI lesions appear as BME and soft tissues edema [16]. With the attenuation of the inflammatory process, in MRI in T1-weighted sequences the lesions may become hyperintense rather than hypointense due to post-inflammatory fatty bone marrow degeneration [17]. Non-specific spondylodiscitis lesions of two or more contiguous vertebrae, with cortical erosions and underlying subchondral sclerosis in the endplates, on either side of an intervertebral disc, mimicking infectious spondylodiscitis, are usually located in the central or anterior part of the discovertebral junction [18]. The intervertebral disc space is usually well preserved; the height may be reduced. The low signal intensity of the disc on fluid-sensitive images and the absence of post-contrastographic enhancement of the disc space help to differentiate the SAPHO from infectious forms. However, the presence of both high signal intensity on T2-weighted images and postcontrastographic disc space enhancement is visible in up to $30 \%$ of cases [17]. The differential diagnosis of SAPHO syndrome compared to infectious spondylodiscitis may also be made difficult by the possible coexistence of prevertebral soft tissue swelling. SAPHO can be a multifocal disease, and total body MRI, with T1-weighted coronal sequences and STIR, is increasingly used to assess this condition [19].

CRMO consists of an autoinflammatory bone disorder that results in bone lesions, usually seen in children (approximately 7-12 years old, 2:1 female-to-male ratio) [20]. Patients usually have non-specific clinical findings and present with localized bone pain in the lower extremities, clavicle, and/or pelvis. One-third of patients has low grade fever. There is an association with other autoimmune disorders like inflammatory bowel diseases, psoriasis, and palmar plantar pustulosis [20].
CRMO is characterized by lytic lesion with a well-defined sclerotic hem. Bone lesions can occur anywhere throughout the body. However, they tend to have a predisposition to the metaphyseal region of bones $(75 \%)$. Spinal involvement is not so rare and often involves different soma with bone edema and vertebral collapse [21]. On MRI, abnormal lesions have increased signal on the STIR sequence and decreased signal on the T1-weighted sequence. Whole body MRI is recommended to determine clinically silent lesions [22].

\section{Modic type 1 lesion}

Modic 1 lesions are alterations involving the subchondral bone of two adjacent vertebrae associated with degenerative disease of the intervertebral disc [23]. Modic 1 lesions are acute conditions, characterized in MRI by a hyperintensity of signal on T2- or STIR-weighted sequences and by hypointensity in T1-weighted sequences, compared to the bone marrow signal (Fig. 4).

Modic 2 lesions represent a chronic phase of the degenerative process, characterized by an isointense signal in T2or STIR-weighted sequences and a higher signal intensity on T1-weighted sequences, considering the signal intensity always in relation to the bone marrow signal (Fig. 5).

Modic 3 lesions are the final stage of the degenerative process, and the main characteristic is the decrease in signal intensity in both STIR/T2 and T1 sequences.

Modic 1 lesions have the potential to mimic infectious changes. The distinction between a Modic 1 lesion and a spondylodiscitis can be made by the lack of abnormal disc signal or disc hypointensity on T2-weighted images. End plates may show enhancement in both degenerative and 
Fig. 4 Sagittal T1-weighted image (a) and sagittal STIR image (b) showing fibrovascular and edematous pattern in the subchondral bone marrow of adjacent vertebral bodies L1/L2 (Modic type 1) (arrowheads). Bony degenerative changes can also be observed at the same level
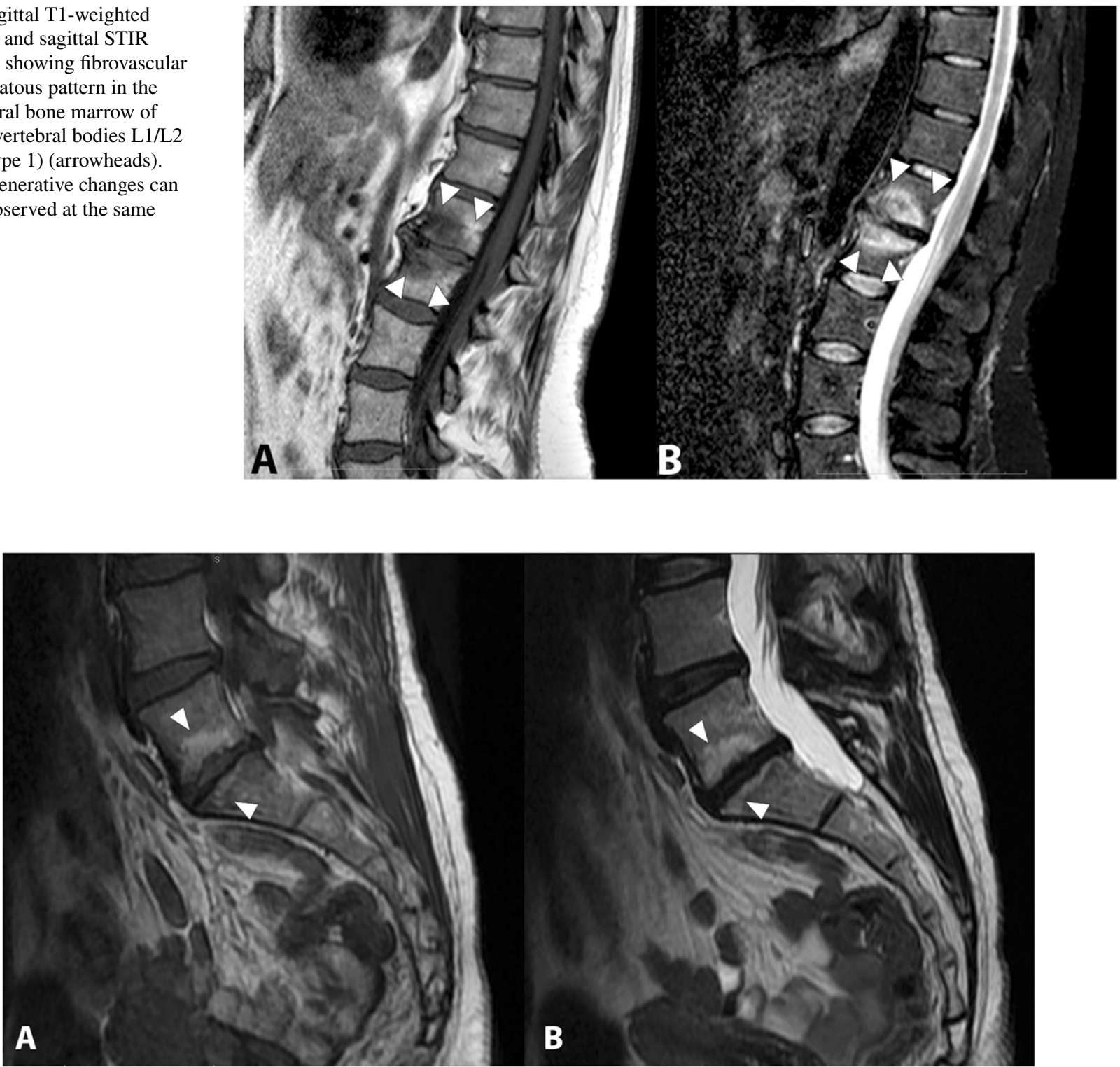

Fig. 5 Sagittal T1-weighted image (a) and sagittal T2-weighted image (b) showing post-inflammatory area of fatty degeneration of the subchondral bone marrow of adjacent vertebral bodies L5/S1 (Modic type 2) (arrowheads)

infectious alterations. Topographically, Modic 1 lesions are usually found at the distal lumbar tract. In population studies, the prevalence of Modic changes is $13 \%$ at lumbar level, and the Modic 2 lesions are largely prevalent $(82 \%)$ over Modic 1 (10.8\%) and Modic 3 (7.2\%) [24].

Modic lesions are easily detected at cervical level and were are associated with neck pain and disc degeneration from 5 to $40 \%$ of the cases. Also at this level, Modic 2 changes are the most frequent [25].

The aetiology of Modic type 1 lesions is still debated. Some authors have hypothesized that these lesions could be secondary to anaerobic germ infection [26]. There is certainly an inflammatory response of the annulus fibrosus characterized by neovascularization around the extruded nucleus pulposus following herniation [27]. The intervertebral degeneration of the disc is characterized by a gradual dehydration of the disc itself and appears in MRI as loss of the normal hyperintensity of the nucleus pulposus in $\mathrm{T} 2$ sequences with consequent loss of disc height. A severely degenerated disc may, however, reveal a T2 signal hyperintensity. In these cases, a degenerated disc may be difficult to differentiate from infectious spondylodiscitis. Degenerative endplate degeneration in Modic 1 lesions may be similar to the BME of endplates observed in spondylodiscitis [28]. Similar to spondylodiscitis, 
inflammatory neovascularization within the subchondral bone is believed to be the cause of BME in Modic 1 lesions [29].

\section{Acute symptomatic calcific discitis}

Calcific discitis (CD) is a well-recognized entity mainly in paediatric patients, but recently it has also been reported in the adult population, present in $5 \%$ of chest $\mathrm{x}$-rays and $6 \%$ of abdominal X-rays [30]. CD is generally an asymptomatic condition, associated with underlying predisposing diseases such as hyperparathyroidism, chondrocalcinosis, or hemochromatosis [31]. CD most commonly occurs in the cervical segment of the spine [32], followed by the thoracic segment, rarely present in the lumbar segment [33]. The diagnosis of $\mathrm{CD}$ is based on imaging techniques. CD in MRI classically shows a low signal central focal lesion in the disc on standard T1- and T2-weighted spin-echo sequences [34]. The MRI may also reveal a swollen intervertebral disc. Early CD may not be radiographically evident and an edematous swollen MRI disc may be the only indication of a CD [35]. There may be diffuse reactive edema of the adjacent vertebra. Contrast enhancement during CD may be seen within the vertebral body if the calcific herniated disc in the vertebral body itself [36].

\section{Spinal gout}

The deposition of monosodium urate in the spine is considered a rare manifestation of gout [37]; however, axial disease seems overlooked since alterations suggestive of monosodium urate deposition in axial structures are detectable in the $17 \%$ of gouty patients [38]. Any segment of the spine may be involved in its components (vertebral bodies, pedicles, lamina, ligaments, interapophyseal cartilage, epidural and intradural spaces). The lumbar region is the most common involved spinal site (78\% of the spinal locations) [38]. The clinical symptoms of spinal gout are non-specific and very varied, ranging from back pain to neurological deficits. Gout involving the endplates of two contiguous vertebral bodies and the intervertebral disc is a condition that can mimic spondylodiscitis [39]. The diagnosis of tophaceous spinal gout is extremely difficult, and the most accurate test to confirm its diagnosis is histological examination. Computed tomography (CT) can help to visualize changes in bone and soft tissue caused by tophi, which appear as a low-density area [40].

Dual energy computed tomography (DECT) can provide additional information respect to conventional $\mathrm{CT}$ in the diagnosis of gout in spinal structures, with a sensitivity between 78 and $100 \%$ and a specificity between $89-100 \%$ in detecting monosodium urate deposition [41].
MRI appears to be sensitive but not specific for the diagnosis of spinal gout, but has the advantage of representing soft tissue changes [42]. Spinal tophi appear at MRI as homogeneous areas of medium to low signal intensity on T1-weighted images. On T2-weighted images, the signal intensity of the tophi varies from homogeneous hyperintensity to homogeneous hypointensity. The signal intensity variations of tophi depend mainly on their degree of hydration and the relative homogeneity of the magnetic field within them. These may be due to the presence of calcifications, mature fibrous tissue or hemosiderin deposits within the tophi [43]. After administration of contrast medium, the tophi show a homogeneous or heterogeneous marginal enhancement. The enhancement of tophi depends on the amount of vascularized inflammatory fibrous tissue. The main differences between spinal gout and spondylodiscitis are the presence, in gout, of spondylolisthesis due to bone erosion of the pars interarticularis and the facet joint, smooth bone erosion predominantly localized in the L5 lower end plate rather than irregular changes, and normal intensity destruction of the bone marrow signal of adjacent vertebrae.

\section{Destructive spondyloarthropathy in long-term haemodialysis}

Destructive spondyloarthropathy (DSA) is increasingly reported as a serious complication of long-term haemodialysis, affecting $8-18 \%$ of dialysis patients [44]. DSA affects single or multiple, contiguous or distant spinal levels. Atlantoaxial involvement is not common [32]. DSA is a radiographic diagnosis based on three findings characterized by severe narrowing of the intervertebral disc spaces, erosions and cystic changes of adjacent vertebral plates, and the absence of significant osteophytosis. The MRI is useful to exclude the presence of infection (absence of high signal strength in T2-weighted sequences) [45]. In MRI, DSA shows alterations generally characterized by low signal intensity in the affected spinal segments in T2-weighted images, even if T2 images with abnormal high signal intensity have been described [46].

\section{Infectious spondylitis}

Spondylodiscitis is generally infection sustained by a single germ, and Staphylococcus aureus is the predominant aetiological agent, affecting about half of non-tubercular infections [47]. The causative agents of granulomatous infections are Mycobacterium tuberculosis and Brucella. Fungal or parasitic infections are rare. The spectrum of clinical manifestations is broad, but pain is the main symptom, regardless of the aetiological agent. Men are affected about twice as often as women, diabetes mellitus is a risk factor. 


\section{Pyogenic spondylodiscitis}

Pyogenic spondylodiscitis generally occurs by haematogenous spread from distant infectious foci in the body, more rarely by contiguity (e.g. oropharynx, pleural space, abdominal cavity) [48]. Most cases are supported by grampositive cocci such as Staphylococcus aureus (Figs. 6, 7), followed by Staphylococcus epidermidis, and Streptococcus spp. [49]. Among the gram-negative bacteria, Escherichia coli is the most commonly isolated pathogen, followed by Enterobacter cloacae, Haemophilus influenzae, Klebsiella pneumonia, and Salmonella enterica. Patients with gramnegative haematogenous spondylodiscitis, compared to those with gram-positive infections, tend to be older individuals with a history of cancer and a recent positive anamnesis for symptomatic urinary tract infection. Gram-negative forms also show a lesser tendency to the formation of abscess cavities [50].

The clinical presentation of spondylodiscitis is variable, but the cardinal clinical sign is the presence of severe pain associated with muscle contracture (present in more than $90 \%$ of cases). Fever and neutrophil leukocytosis are present

Fig. 6 Lumbar (L4-L5) spondylodiscitis caused by Staphylococcus aureus. The whole vertebral body of L4 and the upper portion of L5-vertebral body show an altered signal intensity in the T1-weighted image (a), in the T2-weighted image (b) and in the fat saturated $\mathrm{T} 2$-weighted image (c) (arrowheads). The L4-L5 disc is involved and it appears thinned, with an increased signal intensity in the $\mathrm{T} 2$-weighted and fat saturated T2-weighted images (arrows)
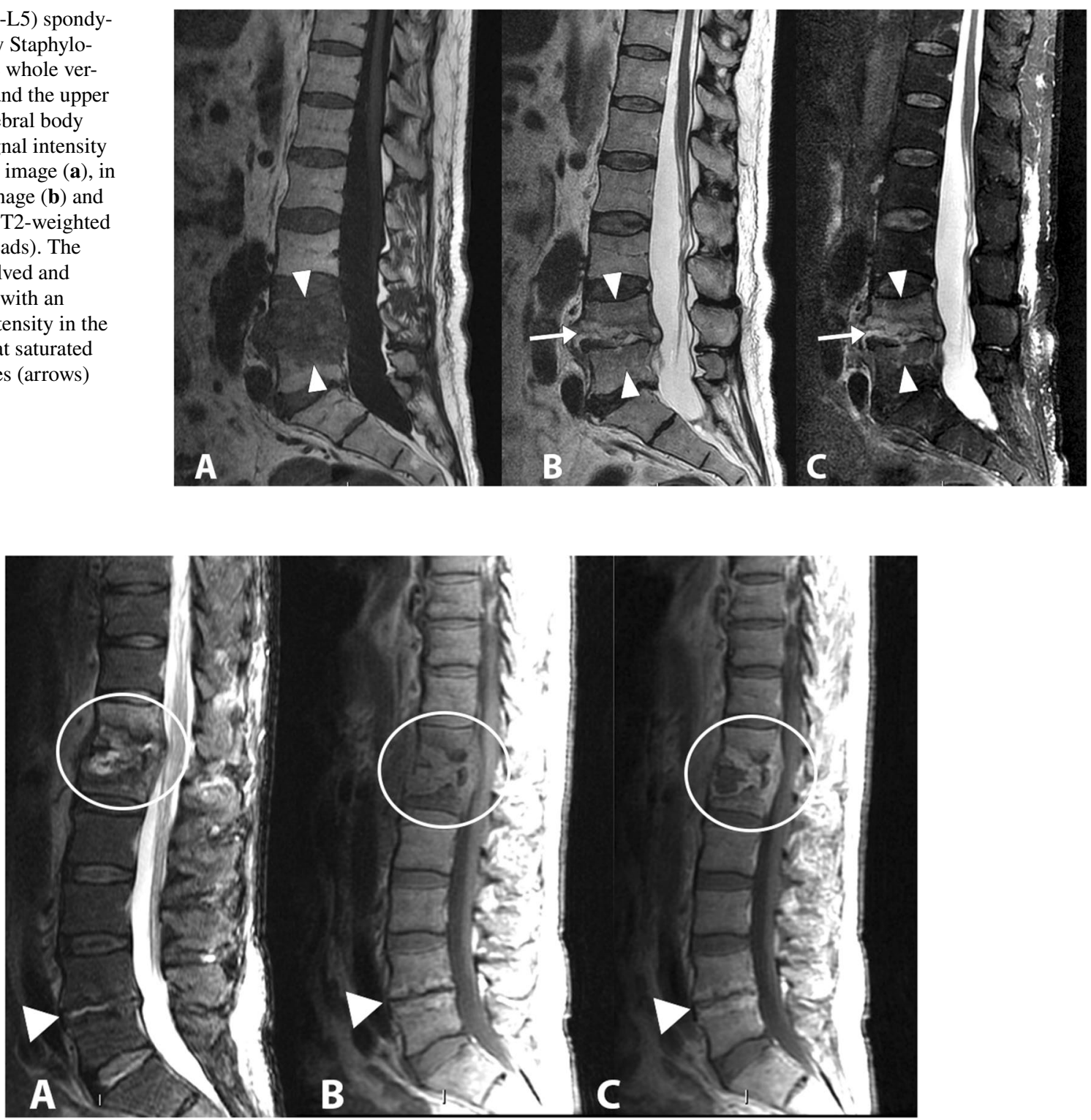

Fig. 7 Spondylodiscitis caused by Staphylococcus aureus. The D12L1 disc and the adjacent vertebral bodies appear markedly involved in the infectious process. The fat saturated T2-weighted sequence (a) and the sagittal T1-weighted sequence (b) show an altered signal intensity of the affected segments. The sagittal T1-weighted image after gadolinium administration (c) highlights a significant contrast enhancement of the affected area, with a posterior extension into the epidural space (white circle). In addition, a Modic 2 lesion can be observed at L4/L5, with hypointense signal in STIR image (a) and high signal intensity in T1-weighted images (b, c) (arrowhead) 
Fig. 8 Gram-positive (Streptococcus spp) lumbar spondylodiscitis. Sagittal (a), coronal (b) and axial T1 fat suppression (c) images after administration of contrast media show enhancement of the L2 and L3 vertebrae and paravertebral soft tissues (white oval) with involvement of the psoas muscles bilaterally (arrowheads)
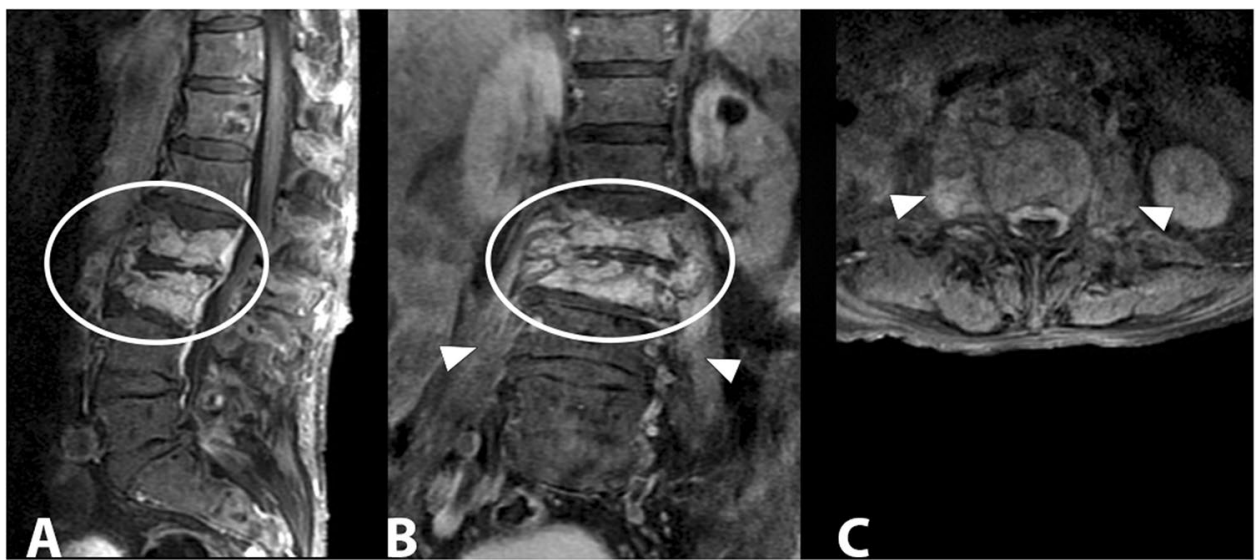

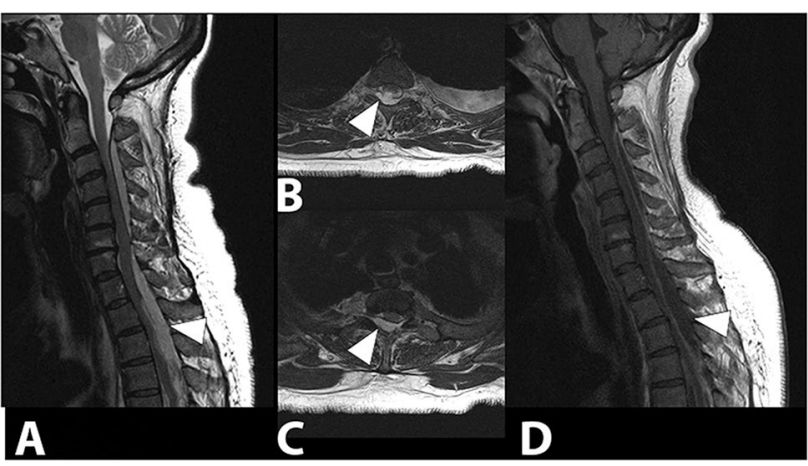

Fig. 9 Sagittal (a) and axial T2-weighted images (b, c) and sagittal T1-weighted fat suppression image with contrast (d). Staphylococcus aureus posterior cervico-dorsal epidural abscesses that compress and displace the spinal cord anteriorly can be observed (arrowhead)

in $40 \%-50 \%$ of cases. Erythrocyte sedimentation rate (ESR) and C-reactive protein (CRP) are almost always increased [51]. Lumbar segments are more frequently involved (48\%) (Fig. 8), followed by dorsal (35\%), and cervical (6.5\%) segments (Fig. 9) [52]. Cervical localization is a rare, but often site of spinal cord compression complications [49]. Possible abscess complications concern the lumbar spine in $2 / 3$ of the cases, with prevalently paravertebral localization (Fig. 10), or the thoracic region in $1 / 3$ of the cases, with prevalently epidural localization.

MRI is the most sensitive technique in the diagnosis of spondylodiscitis. Although it is the most sensitive tool for early detection of signs of infection, MRI results may lag behind clinical symptoms. If the clinical picture is uncertain, an MRI one week after the previous one may be useful to show an evolution. Sagittal-weighted T1 images typically show hypointense and poorly defined vertebral bone marrow in contiguous vertebral bodies. Intervertebral disc space is involved with loss of end plate definition on both sides of the disc. Weighted spin-echo T2 images detect increased water content expression of inflammatory exudate. Intravenous

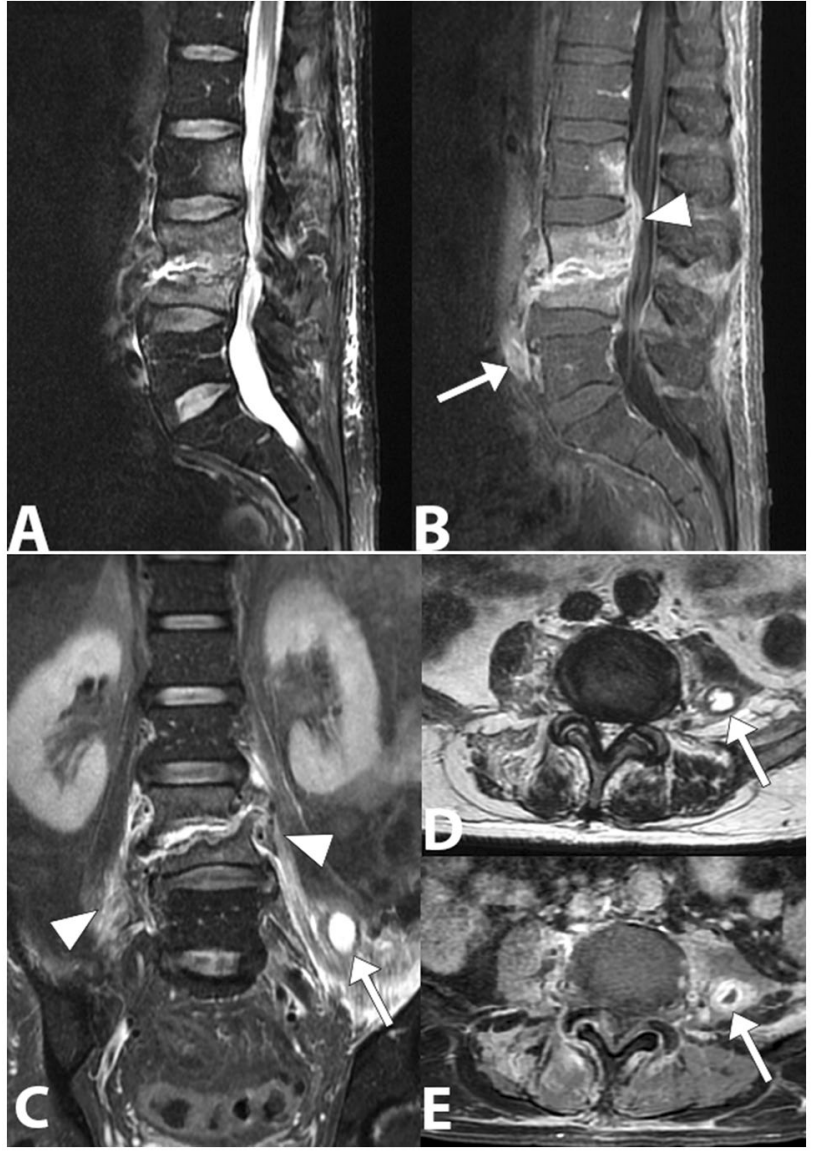

Fig. 10 Gram-negative (Escherichia coli) spondylodiscitis. Sagittal lumbar spine MRI image (a) showing a high bone marrow signal and partial collapse of the vertebral bodies L3 and L4, destruction of the L3-L4 disc and loss of the definition of the end plate on both sides of the disc. In the T1-weighted sagittal image obtained with saturation of the fat signal and after the injection of the contrast medium (b), a better definition of the involvement of the paravertebral (arrow) and epidural space with narrowing of the vertebral canal (arrowhead) can be observed. The posterior L2 vertebral body is also involved. In coronal STIR image (c), axial T2- weighted (d) and axial T1- weighted with fat saturation and gadolinium (e), edema and inflammatory exudate can be observed in the paravertebral soft tissue (arrowheads) and abscesses in the left psoas muscle (arrow) 
gadolinium contrast is usually administered in all suspected cases of spondylodiscitis. In patients who cannot receive gadolinium contrast, diffusion-weighted imaging (DWI) can be used.

\section{Infectious granulomatous diseases}

Some infectious processes within the spinal elements can lead to the formation of granulomas [53]. The organisms causing granulomatous inflammation include various bacteria, fungi or other parasites. Among the bacteria, those most frequently found are Mycobacterium tuberculosis and Brucella. The onset of granulomatous infections is often insidious and often leads to a late diagnosis.

\section{Tubercular spondylodiscitis}

Spinal involvement in tuberculosis (Pott's disease) occurs mainly by haematological spread. The clinical presentation of vertebral tuberculosis is insidious, with symptoms that can last up to 3 years before diagnosis [54]. From an epidemiological point of view, tubercular spondylodiscitis is significantly more common in patients under 40 years of age than in patients older [55].

Thoracolumbar region is the most commonly affected site, while the cervical and sacrum regions are less commonly involved. Usually more than one vertebra is affected because of its segmental arterial distribution and subligamentous spread of the disease.

Tubercular spondylodiscitis usually begins in the anteroinferior part of the vertebral body. The spread of infection occurs under the anterior longitudinal ligament, a structure that involves adjacent vertebral bodies. The narrowing of the disc space occurs secondarily and is not as pronounced as in pyogenic infections. The relative saving of the intervertebral disc appears to be due to the lack of proteolytic enzymes in Mycobacterium tuberculosis [56]. MRI is the diagnostic technique of choice, more sensitive than X-ray and more specific than CT in the diagnosis of spinal tuberculosis. MRI demonstrates involvement of vertebral bodies, disc destruction, cold abscess, vertebral collapse and spinal deformities (Fig. 11). Compared to pyogenic infections, the disc may not show a signal increase in T2-weighted images [57]. The involvement of posterior elements is more common in tubercular infections than in pyogenic infections. Posterior lesions enter into differential diagnosis with neoplastic lesions, particularly when there is relative preservation of disc space. Tubercular infections classically spread to adjacent ligaments and soft tissue in an antero-lateral direction (Fig. 12). The paravertebral abscesses are surrounded by a rim characterized by a robust and irregular enhancement, which can be seen in MRI. These abscesses tend to be larger in tubercular infections than in pyogenic infections (Fig. 13).

Abscess formation is common and can grow to a very large size. The site of cold abscess depends on the region of the vertebral column affected. In the cervical region, the pus accumulates behind prevertebral fascia to form a retropharyngeal abscess. The abscess may track down to the mediastinum to enter into the trachea, oesophagus, or the pleural cavity. In the thoracic spine, the cold abscess usually presents as a fusiform or bulbous paravertebral swellings. At lumbar vertebrae, cold abscesses most commonly present as a swelling in the groin and thigh and pus collection can spread to the gluteal region $[58,59]$.

\section{Brucellar spondylodiscitis}

Brucellosis can account for up to about half of spinal infections in areas where the zoonosis is endemic, being the predominant cause in some case series in the Mediterranean basin and the Middle East [55]. The aetiological agent is Brucella melitensis, an intracellular bacterium [60].
Fig. 11 D6-D7 tubercular spondylodiscitis. In the sagittal T1 image (a), morphostructural alterations of the D6 and D7 with collapse and wedging of the vertebral bodies, accentuation of the physiological dorsal kyphosis, absence of the disc space and partial vertebral fusion can be observed. In the coronal $\mathrm{T} 1$ image with contrast (b), T2 (c) and T1 axial with contrast (d), bilateral paravertebral infectious collections are detected (arrowheads)

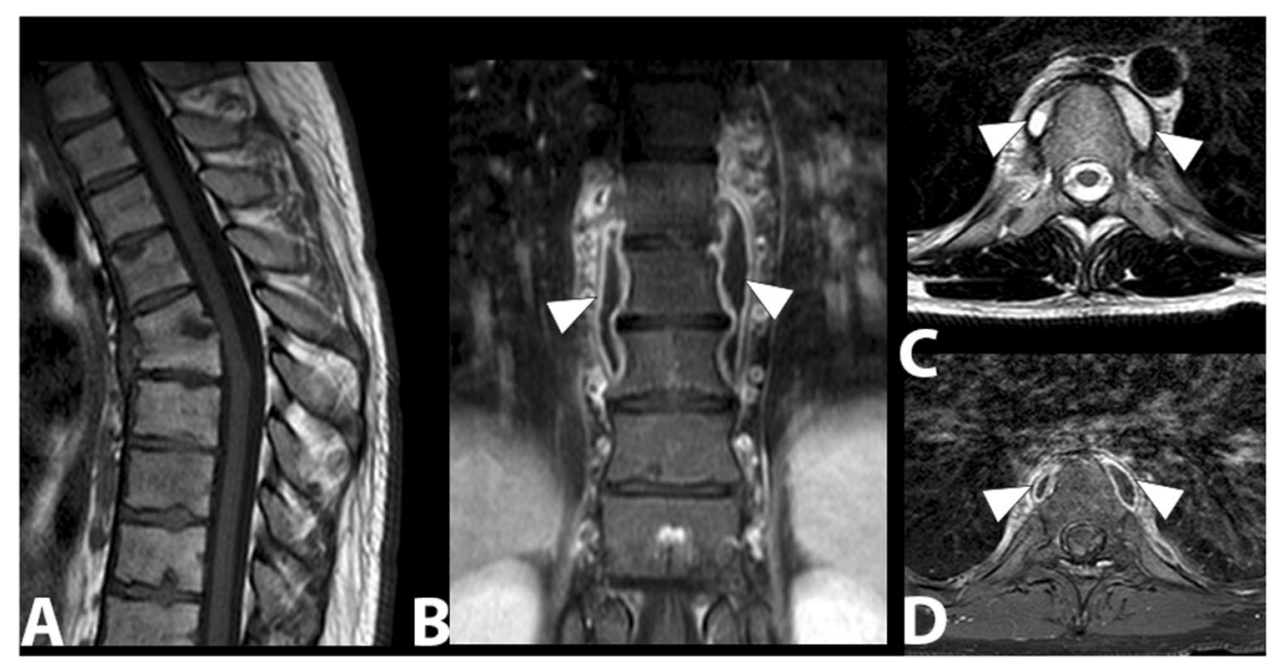


Fig. 12 Lumbar tubercular spondylodiscitis. Sagittal STIR (a), sagittal T1 without contrast (b), sagittal T1 with contrast (c) images demonstrating severe osteo-structural alteration of the L3 vertebral body with invasion of the epidural space, dural sac and spinal roots compression (arrowhead). Axial (d) and coronal (e) T1-weighted images with contrast show paravertebral abscesses affecting the psoas muscles bilaterally (arrows)
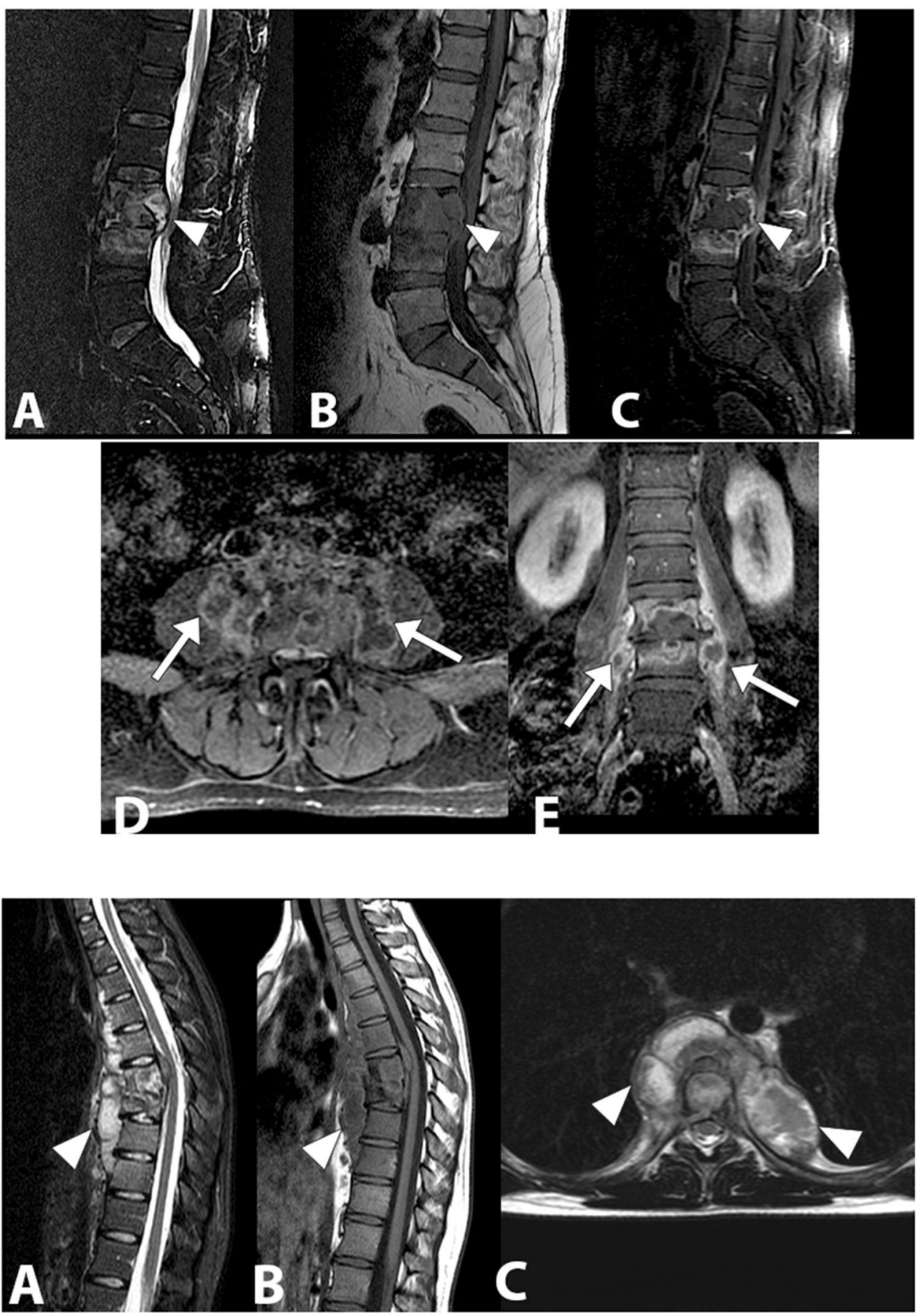

Fig. 13 Tubercular spondylodiscitis with altered signal and morphology of vertebral bodies D7 and D8 in sagittal STIR (a) and T1-weighted images (b), absence of intervertebral disc space D7-D8 and presence of paraspinal abscesses extended from D3 to D9, better assessable in axial images (c) (arrowheads)
Osteoarticular involvement is a common complication of brucellosis, found in up to $85 \%$ of patients [61]. In decreasing order of frequency, spinal involvement concerns the lumbar $(60 \%)$, sacral (19\%) and cervical (12\%) vertebrae [62]. Spondylodiscitis during brucellosis can be multifocal. This type of involvement can be observed in 3-14\% of patients [63]. Spinal brucellosis usually starts from the upper terminal vertebral end plate, but sometimes the lower terminal end plate may also be involved. In MRI, the lesion is detectable as a destructive aspect at the antero-superior vertebral angle accompanied by prominent osteosclerosis, and it is a pathognomonic sign (Pedro Pons' sign) [64]. The intervertebral disc can be infected without spondylitis, being only a discitis. Epidural abscess is a rare complication of spinal brucellosis, but can lead to severe neurological outcomes.

\section{Fungal vertebral infections}

Fungal spondylodiscitis is rare (up to $1.6 \%$ ) even in larger case series; however, the incidence of these conditions 
is increasing as the population of immunocompromised patients increases [65]. Candida spp., Aspergillus spp. and Cryptococcus neoformans are present worldwide, while dimorphic fungi such as Coccidioides immitis and Blastomyces dermatitidis are only endemic in some geographical areas. Spinal fungal infection includes spondylodiscitis, osteomyelitis and meningitis.

MRI features, such as focal partial soft tissue abnormality and partial involvement of the disc/endplate, in combination with clinical features may help to predict fungal discitis/ osteomyelitis [66].

\section{Candida}

Although there are at least 10 species of Candida pathogenic to humans, Candida albicans is responsible for more than half of all cases of spondylodiscitis supported by Candida spp., followed by Candida tropicalis (19\%) (Fig. 14), and Candida glabrata (formerly Torulopsis glabrata, 14\%). Spondylodiscitis supported by Candida glabrata is becoming increasingly common. Overall, Candida spp. is responsible for $0.7-2.7 \%$ of spinal infections [67]. The lower dorsal and lumbar vertebral segments are the most frequently involved sites. The few reported cases occurring at a higher spinal or sacral level are anecdotal. At diagnosis, $83 \%$ of patients have been complaining of back pain for at least one month, while only $32 \%$ of patients are febrile [68].
MRI is the imaging mode of choice and the vertebral bodies and discs typically present hypointense in $\mathrm{T} 1$ and hyperintense in T2. Administration of contrast agent can improve sensitivity and specificity particularly in early infections [69].

\section{Aspergillus}

Aspergillus fumigatus is the most frequently isolated species in bone infections. The lumbar region is the main area $(63 \%)$ of bone involvement, followed by extra-axial regions such as tibia, ribs, wrist, sternum, pelvis and knee [70]. Spondylodiscitis supported by Aspergillus shares several common features with other causes of pyogenic vertebral spondylodiscitis, including male preference, predominance of lumbar involvement, and pain as a symptom of onset.

In the presence of an Aspergillus infection, discs lack signal hyperintensity on T2-weighted and STIR images, due to the presence of the paramagnetic and ferromagnetic elements within the fungi and the nuclear cleft may be preserved, a very uncommon finding in pyogenic spondylitis.

As in tuberculosis, subligamentous spread of abscess and multilevel involvement of the spine can be observed and the intervertebral disc may be spared from invasion and inflammatory changes [71].

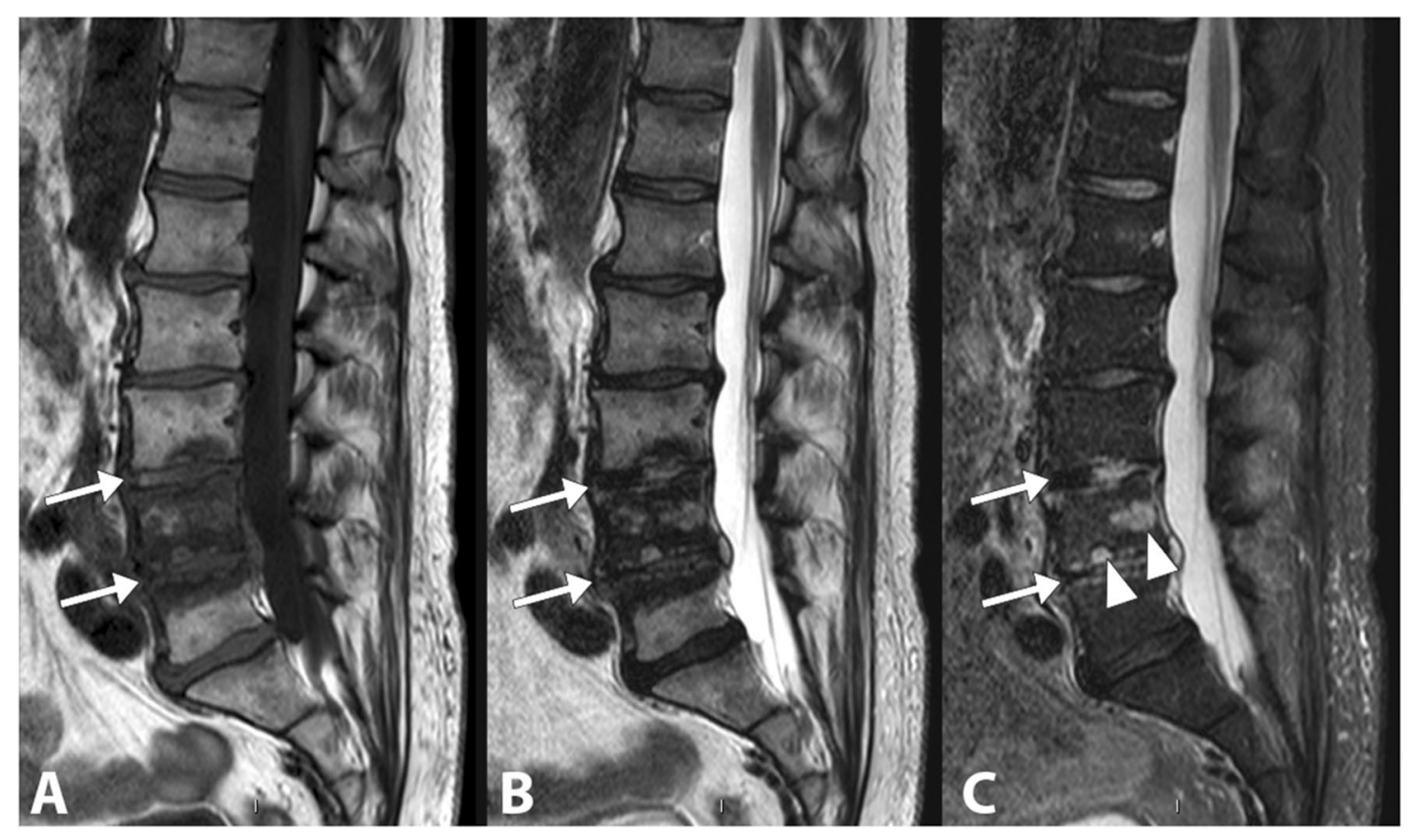

Fig. 14 Gradually resolving lumbar (L3-L4-L5) spondylodiscitis caused by Candida tropicalis. The sagittal T1-weighted (a), T2-weighted (b) and fat saturated T2-weighted (c) images show an altered signal intensity in correspondence with the L3-L4 and L4-L5 discs (arrows). Some infectious foci are still visible in the vertebral body of L4 (arrowheads) 


\section{Cryptococcus}

Cryptococcus neoformans is the fungus that most commonly causes central nervous system diseases in humans. Spinal involvement occurs in up to $10 \%$ of adult cryptococcosis patients, with characteristics similar to those of cold abscesses of tubercular spondylodiscitis [72]. Vertebrae are the most common site of bone involvement in cryptococcosis, the lumbar region being the most affected segment followed by the cervical region [73].

\section{Coccidioidomycosis}

Coccidioides immitis causes bone localization in up to $50 \%$ of patients with diffuse disease [74]. The most involved articular segments are the spine, ribs and pelvis [75]. Vertebral localizations may involve one or more vertebral bodies, paraspinal tissue and contiguous ribs. Intervertebral discs are relatively spared. Vertebral collapse and fistulae are uncommon late manifestations. In contrast to tuberculosis, in coccidioidomycosis spondylitis the gibbous deformity is not common, although reported [76]. MRI images are not specific, and diagnosis is usually made by biopsy in patients from endemic areas.

\section{Blastomycosis}

Skeletal localizations are observed in 14-60\% of cases of diffuse blastomycosis. The spine is the most commonly involved skeletal site, followed by the skull, ribs, tibia and bones of the foot and wrist [77]. The lower dorsal spine and lumbar segments are the most affected regions, similarly to tuberculosis. The anterior aspect of the vertebral body is usually involved in the early stages. Even non-adjacent vertebrae can be affected by infection along the anterior longitudinal ligament. This can cause gross deformities of the vertebral spine. Paravertebral abscesses or iliopsoas muscle can be documented.

\section{Parasitic spinal infections}

Several parasites affecting the central nervous system can affect the spine. The most common of these diseases is cysticercosis. In endemic regions, schistosomiasis is a common cause of spinal involvement. Toxoplasmosis is a pathogen frequently found in immunodepressed patients. Echinococcosis and hydatidosis are also emerging parasitic diseases in some parts of the world. Although the definitive diagnosis of a spinal parasitosis is usually confirmed by histological biopsy examination, the clinical suspicion is generally based on a combination of epidemiological, clinical, serological, and neuroimaging features.

\section{Cysticercosis}

Cysticercosis, the most common central nervous system parasitosis, is caused by Taenia solium [78]. Neurocysticercosis involving the spinal cord is extremely rare. Because of the mass effect and limited space within the canal compared to intracranial space, spinal cysticercosis is more likely to cause neurological impairment. Neurological deficits are secondary to the mass effect of cysts and the inflammatory reaction after treatment.

\section{Schistosomiasis}

Schistosomiasis is a parasitosis caused by Schistosoma platyhelminthes. Schistosoma japonicum, Schistosoma mansoni and Schistosoma haematobium can cause pathology in humans [79]. Spinal cord injuries are often caused by Schistosoma mansoni and Schistosoma haematobium. MRI is the imaging mode of choice to assist in the diagnosis of schistosomiasis with spinal localization. MRI can document an enlargement of the spinal cord caused by the formation of intramedullary granulomas, particularly in the lower spinal cord region and the conus medullaris region [80]. Schistosomal intramedullary granulomas are usually seen isointense in relation to the cord, or as heterogeneous hyperintense lesion with an unclear boundary, or as multiple patchy nodular lesions resembling a string of beads mainly in the ventral spinal cord which may be significantly enhanced. Atrophy of the spinal cord may be seen in longstanding cases [81].

\section{Toxoplasmosis}

Toxoplasmosis is the most common opportunistic infection of the central nervous system [82]. The disease is caused by Toxoplasma gondii, obligate intracellular protozoon. At MRI, the lesions are hyperintense on T2-weighted sequences and show increased contrast after gadolinium administration on T1-weighted sequences. Localized intramedullary ring-enhancing lesions are commonly seen in MRI during toxoplasmosis [83]. In case of a regular spinal cord size, the presence of an abnormal spinal signal may suggest a vacuolar myelopathy. An enlargement of the spinal cord is suggestive of the presence of Toxoplasma myelitis.

\section{Echinococcosis/hydatidosis}

Echinococcus granulosus is a parasitic zoonosis commonly involving liver and lungs. The skeletal localization of hydatid cysts is a rare occurrence, when it occurs it affects the spine in almost $50 \%$ of cases [84]. Spinal hydatid cysts 
account for $1 \%$ of all cases of hydatid disease [85]. The most common spinal site of extramedullary intradural hydatid cysts is the dorsal region (46.5\%), followed by the lumbar (30.2\%) and cervical region (9.3\%). Hydatid cysts can be unilocular or multilocular, the first type being more common (57.5\%) [86]. In hydatid disease, spinal involvement is classified into five groups: (1) primary intramedullary hydatid cyst; (2) intramedullary extramedullary intradural hydatid cyst; (3) extradural intraspinal hydatid cyst; (4) vertebral hydatid disease; (5) paravertebral hydatid disease. The first three types of this group are considered rare [87].

On MRI T1-weighted images, the hydatid cyst wall may be isointense or give a slightly lower signal than its content, and $\mathrm{T} 2$-weighted images show a low-intensity border surrounding the homogeneous high signal cyst content. The hydatid cyst wall shows a slight contrast enhancement. The low signal rim on $\mathrm{T} 2$-weighted images results from reactive fibrosis and degeneration around the parasite membrane. The T2-weighted images give information on the vitality of the hydatid cyst: a decrease in the high signal and an increase in the low signal of the collapsed cystic walls indicate a failing cyst.

\section{Differential diagnosis}

MRI allows to identify some specific signs of the various infectious spondylodiscitis. The main features of the pyogenic spondylodiscitis are the involvement of the lumbar spine, poor enhancement of the paravertebral tissues, diffuse/homogeneous vertebral contrast enhancement, low degree destruction of the vertebral bodies, hyperintense/homogeneous signal of the vertebral bodies on T2-weighted images.

Tubercular spondylodiscitis is mainly characterized by relative disc preservation and other features such as intraosseous abscesses, large paravertebral abscesses, skip lesions, contiguous subligamentous diffusion, involvement of posterior elements and invasion of the vertebral canal and nerve roots [88] (Table 2). In tubercular spondylodiscitis, the size of paraspinal abscesses is usually larger than that of brucellar forms. The involvement of posterior spinal elements, in particular the involvement of pedicles, is generally not a feature of spinal tuberculosis $[89,90]$. The upper lumbar spine and lower thoracic spine are the

Table 2 Clinical and MRI features to differentiate tubercular from pyogenic infections ( modified from: Frel et al. [95])

\begin{tabular}{|c|c|c|}
\hline & Pyogenic spondylitis & Tuberculous spondylitis \\
\hline \multicolumn{3}{|l|}{ Patient characteristics and clinical symptoms } \\
\hline Age & Relatively old & Relatively young \\
\hline Duration to diagnosis & Relatively short symptom to diagnosis interval & Relatively long symptom to diagnosis interval \\
\hline History & $\begin{array}{l}\text { Recent distant bacterial infection or previous } \\
\text { spinal surgery }\end{array}$ & $\begin{array}{l}\text { History of TBC infection or current extraspi- } \\
\text { nal manifestations }\end{array}$ \\
\hline Onset & Acute or subacute & Subacute \\
\hline Fever & $\begin{array}{l}\text { More frequent associated high fever, acute } \\
\text { sepsis }\end{array}$ & Intermitted fever \\
\hline ESR, CRP, WCC & Markedly increased & Mild increased \\
\hline \multicolumn{3}{|l|}{ MRI features } \\
\hline Involvement of vertebral bodies & Involvement $\leq 2$ vertebral bodies & Multiple body involvement \\
\hline Severity of destruction of vertebral bodies & Infrequent and mild to moderate & Frequent and more severe \\
\hline Disc destruction & Severe to complete disc destruction & Normal to mild disc destruction \\
\hline Loss of cortical definition & Absent & Present \\
\hline Areas of paraspinal enhancement & Poorly demarcated contrast & Well-demarcated contrast \\
\hline Vertebral signal in $\mathrm{T} 2$ images & Hyperintense/homogeneous & Heterogeneous \\
\hline Vertebral enhancement & Diffuse/homogeneous & Focal/heterogeneous \\
\hline Paraspinal abscess & $39-40 \%$ of cases & $75 \%$ of cases \\
\hline Epidural abscess & $11-15 \%$ of cases & $56-60 \%$ of cases \\
\hline Abscess wall & Thick and irregular & Thin and smooth \\
\hline $\begin{array}{l}\text { Meningeal enhancement at the affected verte- } \\
\text { bral level }\end{array}$ & $28-30 \%$ of cases & $>75 \%$ of cases \\
\hline $\begin{array}{l}\text { Subligamentous spread to } 3 \text { or more vertebral } \\
\text { bodies }\end{array}$ & Absent & Present \\
\hline Spinal deformity & Absent & Present \\
\hline Thoracic spine involvement & Absent & Present \\
\hline
\end{tabular}

$M R I$ magnetic resonance imaging, $E S R$ erythrocyte sedimentation rate, $C R P$ C-reactive protein, $W C C$ white cell count 
most frequently involved sites. More than one vertebra is typically affected, and the vertebral bodies are more frequently affected than the posterior arches.

An almost intact vertebral architecture is observed in brucellar spondylodiscitis, despite evidence of widespread vertebral infection. An increase in the signal intensity of the disc on T2-weighted and high-contrast images, as well as the involvement of the articular facets, is also typical [91]. Paravertebral abscesses tend to be smaller than those of tubercular infections [92]. In the acute ( $<3$ months) and subacute (3-12 months) phases, brucellar spondylodiscitis may mimic tuberculosis. In these phases, the more homogeneous intensity of the high-intensity vertebral signal on STIR sequences and the almost intact vertebral height seem to suggest the diagnosis of brucellar spondylodiscitis instead of tuberculosis [93].

Most fungal spinal infections have no MRI imaging peculiarities. The destruction of the vertebral body in this type of disease may mimic tubercular spondylitis. The absence of signal enhancement on T2-weighted images and low or undetectable enhancement after contrast administration may be MRI features of fungal infections [94]. MRI may overestimate the extent of infected tissue. Therefore, additional information from conventional radiology or CT may be required to define the actual amount of tissue necrosis. Table 2 summarizes the characteristics that differentiate individual spondylodiscitis types [95].

\section{Conclusions}

Spondylodiscitis involve the vertebral bodies, the intervertebral disc, and may involve the paravertebral structures and the spinal canal. If not recognized and treated early, morbidity and mortality rates are potentially high. The incidence of spondylodiscitis has increased in recent years due to an increase in the immunodepressed population but also due to improved diagnostic accuracy. However, the diagnosis remains challenging because the disease can have an insidious onset, with sometimes non-specific clinical features. MRI is the most sensitive technique for the diagnosis of spondylodiscitis. It allows diagnosis in the absence of radiographic signs and can provide indications on the aetiological agent. However, specific differentiation of spondylodiscitis subtypes based on MRI finding seems to be difficult, particularly when some of the classic imaging features are absent or when there are unusual patterns of infectious spondylitis. Moreover, non-infectious inflammatory diseases and degenerative disease may simulate spinal infection.

According to the role of MRI in the follow-up of treated patients with spondylodiscitis, the 2015 American Society guidelines do not recommend follow-up MRI in patients in whom a favourable clinical and laboratory response to antimicrobial therapy was observed [96].

The limits of MRI are mainly the limited availability and accessibility of the machines, and the execution time of examinations. Future research should focus on further validation of lesions detectable in MRI in extensive prospective studies.

Authors' contributions FS conceived the paper and was the major contributor in drafting the article. LC, MC, MDC, GP, GF, RG and AG collected the images and performed the literature review. All the authors revised the paper for important intellectual content. All the authors approved the final manuscript to be published.

Funding Open access funding provided by Università Politecnica delle Marche within the CRUI-CARE Agreement. Not applicable.

Availability of data and materials Not applicable.

Code availability Not applicable.

\section{Declarations}

Conflict of interest The authors declare that they have no conflict of interest.

Ethics approval Not applicable.

Consent to participate Not applicable.

Consent for publication Not applicable.

Ethical standards This article does not contain any studies with human participants performed by any of the authors.

Open Access This article is licensed under a Creative Commons Attribution 4.0 International License, which permits use, sharing, adaptation, distribution and reproduction in any medium or format, as long as you give appropriate credit to the original author(s) and the source, provide a link to the Creative Commons licence, and indicate if changes were made. The images or other third party material in this article are included in the article's Creative Commons licence, unless indicated otherwise in a credit line to the material. If material is not included in the article's Creative Commons licence and your intended use is not permitted by statutory regulation or exceeds the permitted use, you will need to obtain permission directly from the copyright holder. To view a copy of this licence, visit http://creativecommons.org/licenses/by/4.0/.

\section{References}

1. Herren C, Jung N, Pishnamaz M, Breuninger M, Siewe J, Sobottke R (2017) Spondylodiscitis: diagnosis and treatment options-a systematic review. Dtsch Arztebl Int 114:875-882

2. Maiuri F, Iaconetta G, Gallicchio B, Manto A, Briganti F (1997) Spondylodiscitis Clinical and magnetic resonance diagnosis. Spine (Phila Pa 1976) 22:1741-1746 
3. Sieper J, Braun J, Dougados M, Baeten D (2015) Axial spondyloarthritis. Nat Rev Dis Primers 1:15013

4. Rudwaleit M, Landewe R, Van Der Heijde D et al (2009) The development of Assessment of SpondyloArthritis international Society classification criteria for axial spondyloarthritis (part I): classification of paper patients by expert opinion including uncertainty appraisal. Ann Rheum Dis 68(6):770-776

5. Sieper J, Rudwaleit M, Baraliakos X et al (2009) The Assessment of SpondyloArthritis International Society (ASAS) handbook: a guide to assess spondyloarthritis. Ann Rheum Dis 68(Suppl. 2):ii1-44

6. Hermann KG, Landewe RB, Braun J et al (2005) Magnetic resonance imaging of inflammatory lesions in the spine in ankylosing spondylitis clinical trials: is paramagnetic contrast medium necessary? J Rheumatol 32:2056-2060

7. Battistone MJ, Manaster BJ, Reda DJ et al (1998) Radiographic diagnosis of sacroiliitis: are sacroiliac views really better? J Rheumatol 25:2395-2401

8. Rudwaleit M, Jurik AG, Hermann KG et al (2009) Defining active sacroiliitis on magnetic resonance imaging (MRI) for classification of axial spondyloarthritis a consensual approach by the ASAS/OMERACT MRI group. Ann Rheum Dis 68:1520-1527

9. Kröber G, Weber U (2018) MRI in spondyloarthritis: when and how? Curr Opin Rheumatol 30(4):324-333

10. Bigot J, Loeuille D, Chary-Valckenaere R et al (1999) Determination of the best diagnostic criteria of sacroiliitis with MRI. J Radiol 80:1649-1657

11. Hermann KG, Baraliakos X, van der Heijde DM et al (2012) Assessment in SpondyloArthritis international Society (ASAS). Descriptions of spinal MRI lesions and definition of a positive MRI of the spine in axial spondyloarthritis: a consensual approach by the ASAS/OMERACT MRI study group. Ann Rheum Dis 71:1278-1288

12. Kabasakal Y, Garrett SL, Calin A (1996) The epidemiology of spondylodiscitis in ankylosing spondylitis: a controlled study. $\mathrm{Br}$ J Rheumatol 35:660-663

13. Park YS, Kim JH, Ry JA, Kim TH (2011) The Andersson lesion in ankylosing spondylitis: distinguishing between the inflammatory and traumatic subtypes. J Bone Jt Surg Br 93(7):961-966

14. Hayem G, Bouchaud-Chabot A, Benali K et al (1999) SAPHO syndrome: a long-term follow-up study of 120 cases. Semin Arthritis Rheum 29:159-171

15. Leone A, Cassar-Pullicino VN, Casale R, Magarelli N, Semprini A, Colosimo C (2015) The SAPHO syndrome revisited with an emphasis on spinal manifestations. Skeletal Radiol 44(1):9-24

16. Earwaker JWS, Cotten A (2003) SAPHO: syndrome or concept? Imaging findings. Skelet Radiol 32:311-327

17. Nachtigal A, Cardinal E, Bureau NJ, Sainte-Marie LG, Milette F (1999) Vertebral involvement in SAPHO syndrome: MRI findings. Skelet Radiol 28:163-168

18. Kotilainen P, Gullichsen RE, Saario R, Manner I, Kotilainen E (1997) Aseptic spondylitis as the initial manifestation of the SAPHO syndrome. Eur Spine J 6(5):327-329

19. Fritz J, Tzaribatchev N, Claussen CD et al (2009) Chronic recurrent multifocal osteomyelitis: comparison of whole-body MR imaging with radiography and correlation with clinical and laboratory data. Radiology 252:842-851

20. Hedrich CM, Hahn G, Girschick HJ et al (2013) A clinical and pathomechanistic profile of chronic nonbacterial osteomyelitis/ chronic recurrent multifocal osteomyelitis and challenges facing the field. Expert Rev Clin Immunol 9(9):845-854

21. Palumbo P, Bruno F, Arrigoni F et al (2020) Diagnostic and interventional management of infective spine diseases. Acta Biomed 91(8-S):125-135
22. Acikgoz G, Averill LW (2014) Chronic recurrent multifocal osteomyelitis: Typical patterns of bone involvement in whole-body bone scintigraphy. Nucl Med Commun 35(8):797-807

23. Nguyen C, Poiraudeau S, Rannou F (2015) From Modic 1 vertebral-endplate subchondral bone signal changes detected by MRI to the concept of 'active discopathy.' Ann Rheum Dis 74(8):1488-1494

24. Kanna RM, Shanmuganathan R, Rajagopalan VR et al (2017) Prevalence, patterns, and genetic association analysis of modic vertebral endplate changes. Asian Spine J 11(4):594-600

25. Yang X, Karis DSA, Vleggeert-Lankamp CLA (2020) Association between Modic changes, disc degeneration, and neck pain in the cervical spine: a systematic review of literature. Spine J 20(5):754-764

26. Albert HB, Sorensen JS, Christensen BS et al (2013) Antibiotic treatment in patients with chronic low back pain and vertebral bone edema (Modic type 1 changes): a double-blind randomized clinical controlled trial of efficacy. Eur Spine J 22:697-707

27. Gronblad M, Virri J, Tolonen J et al (1994) A controlled immunohistochemical study of inflammatory cells in disc herniation tissue. Spine (Phila Pa 1976) 19:2744-2751

28. Shrot S, Sayah A, Berkowitz F (2017) Can the pattern of vertebral marrow oedema differentiate intervertebral disc infection from degenerative changes? Clin Radiol 72(7):613.e7-613.e11

29. Modic MT, Steinberg PM, Ross JS et al (1988) Degenerative disk disease: assessment of changes in vertebral body marrow with MR imaging. Radiology 166:193-199

30. Nogueira-Barbosa MH, da Silva Herrero CF, Pasqualini W DHL (2013) Calcific discitis in an adult patient with intravertebral migration and spontaneous remission. Skeletal Radiol 42(8):1161-1164

31. Chanchairujira K, Chung CB, Kim JY et al (2004) Intervertebral disk calcification of the spine in an elderly population: radiographic prevalence, location, and distribution and correlation with spinal degeneration. Radiology 230(2):499-503

32. Salaffi F, Carotti M, Di Carlo M et al (2020) Craniocervical junction involvement in musculoskeletal diseases: an area of close collaboration between rheumatologists and radiologists. Radiol Med 125(7):654-667

33. Spapens N, Wouters C, Moens P (2010) Thoracolumbar intervertebral disc calcifications in an 8-year-old boy: case report and review of the literature. Eur J Pediatr 169(5):577-580

34. Bangert BA, Modic MT, Ross JS et al (1995) Hyperintense disks on T1-weighted MR images: correlation with calcification. Radiology 195(2):437-443

35. Swischuk LE, Stansberry SD (1991) Calcific discitis: MRI changes in discs without visible calcification. Pediatr Radiol 21(5):365-366

36. Bazzi J, Dimar JR, Glassman SD (2002) Acute calcific discitis in adults. Am J Orthop (Belle Mead NJ) 31(3):141-145

37. Toprover M, Krasnokutsky S, Pillinger MH (2015) Gout in the spine: imaging, diagnosis, and outcomes. Curr Rheumatol Rep 17(12):70

38. Saketkoo LA, Robertson HJ, Dyer HR et al (2009) Axial gouty arthropathy. Am J Med Sci 338(2):140-146

39. Zhou S, Xiao Y, Liu X, Zhong Y, Yang H (2019) Gout involved the cervical disc and adjacent vertebral endplates misdiagnosed infectious spondylodiscitis on imaging: case report and literature review. BMC Musculoskelet Disord 20(1):425

40. Carotti M, Salaffi F, Ciapetti A (2010) Computed tomography in tophaceous gout. J Rheumatol 37(6):1267-1268

41. Wang JX, Ng B, Bak H et al (2020) The utility of dual energy computed tomography in the management of axial gout: case reports and literature review. BMC Rheumatol 4:22 
42. McQueen FM, Doyle A, Dalbeth N (2011) Imaging in gout-what can we learn from MRI, CT, DECT and US? Arthritis Res Ther 13(6):246

43. Yen PS, Lin JF, Chen SY, Lin SZ (2005) Tophaceous gout of the lumbar spine mimicking infectious spondylodiscitis and epidural abscess: MR imaging findings. J Clin Neurosci 12(1):44-46

44. Khalfallah M, Faure A, Hamel O et al (2005) La spondylarthropathie érosive du dialysé rénal. A propos d'un cas, revue de la littérature [Dialysis-associated spondyloarthropathy. Case report and literature review]. Neurochirurgie 51(3-4 Pt 1):165-172

45. Karakida O, Aoki I, Kanno Y et al (1997) Hemodialysis-related arthropathy. A prospective MR study with SE and GRE sequences. Acta Radiologicam 38:158-164

46. Theodorou DJ, Theodorou SJ, Resnick D (2002) Imaging in dialysis spondyloarthropathy. Semin Dial 15(4):290-296

47. Kapsalaki E, Gatselis N, Stefos A et al (2009) Spontaneous spondylodiscitis: presentation, risk factors, diagnosis, management, and outcome. Int J Infect Dis 13(5):564-569

48. Resnick D, Niwayama G (1995) Osteomyelitis, septic arthritis, and soft tissue infection: axial skeleton. In: Resnick D, Niwayama G (eds) Diagnosis of bone and joint disorders, vol 4. WB Saunders, Philadelphia, pp 2419-2447

49. Gentile L, Benazzo F, De Rosa F et al (2019) A systematic review: characteristics, complications and treatment of spondylodiscitis. Eur Rev Med Pharmacol Sci 23(2 Suppl):117-128

50. Lee CY, Wu MH, Cheng CC et al (2016) Comparison of gramnegative and gram-positive hematogenous pyogenic spondylodiscitis: clinical characteristics and outcomes of treatment. BMC Infect Dis 16(1):735

51. Leal FS, de Tella OI, Bonatelli Ade PL et al (2003) Septic spondylodiscitis: diagnosis and treatment. Arq Neuropsiquiatr 61(3-B):829-835

52. Quiñones-Hinojosa A, Jun P, Jacobs R, Rosenberg WS, Weinstein PR (2004) General principles in the medical and surgical management of spinal infections: a multidisciplinary approach. Neurosurg Focus 17(6):E1

53. Murray MR, Schroeder GD, Hsu WK (2015) Granulomatous vertebral osteomyelitis: an update. J Am Acad Orthop Surg 23(9):529-538

54. DeSanto J, Ross JS (2011) Spine infection/inflammation. Radiol Clin North Am 49(1):105-127

55. Gouliouris T, Aliyu SH, Brown NM (2010) Spondylodiscitis: update on diagnosis and management. J Antimicrob Chemother 65(Suppl 3):iii11-iii24

56. Chapman M, Murray RO, Stoker DJ (1979) Tuberculosis of the bones and joints. Semin Roentgenol 14:266-282

57. Sharif HS, Clark DC, Aabed MY et al (1991) MR imaging of mycetoma: comparison with CT. Radiology 178:865-870

58. Jain AK (2010) Tuberculosis of the spine: a fresh look at an old disease. J Bone Jt Surg Br 92(7):905-913

59. McLain RF, Isada C (2004) Spinal tuberculosis deserves a place on the radar screen. Cleve Clin J Med 71(7):543-549

60. Seleem MN, Boyle SM, Sriranganathan N (2010) Brucellosis: a re-emerging zoonosis. Vet Microbiol 140:392-398

61. Ulu-Kilic A, Karakas A, Erdem H et al (2014) Update on treatment options for spinal brucellosis. Clin Microbiol Infect 20:75-82

62. Bozgeyik Z, Aglamis S, Bozdag PG, Denk A (2014) Magnetic resonance imaging findings of musculoskeletal brucellosis. Clin Imaging 38:719-723

63. Chelli Bouaziz M, Ladeb MF, Chakroun M, Chaabane S (2011) Spinal brucellosis: a review. Skeletal Radiol 37:785-790

64. Tuna N, Ogutlu A, Gozdas HT, Karabay O (2011) Pedro Pons' sign as a Brucellosis complication. Indian J Pathol Microbiol $54: 183-184$
65. Williams RL, Fukui MB, Meltzer CC et al (1999) Fungal spinal osteomyelitis in the immunocompromised patient: MR findings in three cases. AJNR Am J Neuroradiol 20:381-385

66. Simeone FJ, Husseini JS, Yeh KJ et al (2020) MRI and clinical features of acute fungal discitis/osteomyelitis. Eur Radiol 30(4):2253-2260

67. Calvo JM, Ramos JL, Garcia F, Bureo JC, Bureo P, Perez M (2000) Pyogenic and non-pyogenic vertebral osteomyelitis: descriptive and comparative study of a series of 40 cases. Enferm Infect Microbiol Clin 18:452-456

68. Miller DJ, Mejicano GC (2001) Vertebral osteomyelitis due to Candida species: case report and literature review. Clin Infect Dis 33:523-530

69. Stolberg-Stolberg J, Horn D, Roßlenbroich S et al (2017) Management of destructive Candida albicans spondylodiscitis of the cervical spine: a systematic analysis of literature illustrated by an unusual case. Eur Spine J 26(4):1009-1018

70. Hummel M, Schuler S, Weber U et al (1993) Aspergillosis with Aspergillus osteomyelitis and diskitis after heart transplantation: surgical and medical management. J Heart Lung Transplant 12:599-603

71. Hong SH, Choi JY, Lee JW et al (2009) MR imaging assessment of the spine: infection or an imitation? Radiographics 29(2):599-612

72. Liu PY (1998) Cryptococcal osteomyelitis: case report and review. Diagn Microbiol Infect Dis 30:33-35

73. Jain M, Sharma S, Jain TS (1999) Cryptococcosis of thoracic vertebra simulating tuberculosis: diagnosis by fine-needle aspiration biopsy cytology-a case report. Diagn Cytopathol 20:385-386

74. McGahan JP, Graves DS, Palmer PE (1980) Coccidioidal spondylosis; usual and unusual radiographic manifestations. Radiology 136:5-9

75. Eller JL, Siebert PE (1969) Sclerotic vertebral bodies. An unusual manifestation of disseminated coccidioidomycosis. Radiology 93:1099-1100

76. Dalinka CM, Greendyke CW (1971) The spinal manifestations of coccidiomycosis. J Can Assoc Radiol 22:93-99

77. Hadjipavlou AG, Mader JT, Nauta HJ, Necessary JT, Chaljub G, Adesokan A (1998) Blastomycosis of the lumbar spine: case report and review of the literature, with emphasis on diagnostic laboratory tools and management. Eur Spine J 7:416-421

78. Leite CC, Jinkins JR, Escobar BE et al (1997) MR imaging of intramedullary and intradural extramedullary spinal cysticercosis. AJR Am J Roentgenol 169:1713-1717

79. Shih RY, Koeller KK (2015) Bacterial, fungal, and parasitic infections of the central nervous system: radiologic-pathologic correlation and historical perspectives. Radiographics 35:1141-1169

80. Silva LC, Maciel PE, Ribas JG, Souza-Pereira SR, Antunes CM, Lambertucci JR (2004) Treatment of schistosomal myeloradiculopathy with praziquantel and corticosteroids and evaluation by magnetic resonance imaging: a longitudinal study. Clin Infect Dis 39:1618-1624

81. Adeel AA (2015) Spinal cord schistosomiasis. Sudan J Paediatr 15(2):23-28

82. Kung DH, Hubenthal EA, Kwan JY, Shelburne SA, Goodman JC, Kass JS (2011) Toxoplasmosis myelopathy and myopathy in an AIDS patient: a case of immune reconstitution inflammatory syndrome? Neurologist 17:49-51

83. Garcia-Gubern C, Fuentes CR, Colon-Rolon L, Masvidal D (2010) Spinal cord toxoplasmosis as an unusual presentation of AIDS: case report and review of the literature. Int J Emerg Med $3: 439-442$

84. Arif S, Zaheer S (2009) Intradural extramedullary primary hydatid cyst of the spine in a child: a very rare presentation. Eur Spine J 18(Suppl 2):179-182 
85. Lakhdar F, Arkha Y, Rifi L, Derraz S, Ouahabi A, Khamlichi A (2009) Spinal intradural extramedullary hydatidosis: report of three cases. Neurosurgery 5:372-377

86. Lotfinia I, Sayyahmelli S, Mahdkhah A, Shoja MM (2013) Intradural extramedullary primary hydatid cyst of the spine: a case report and review of literature. Eur Spine J 22(Suppl 3):S329-S336

87. Braithwaite P, Lees R (1981) Vertebral hydatid disease: radiological assessment. Radiology 140:763-766

88. Trecarichi EM, Di Meco E, Mazzotta V, Fantoni M (2012) Tuberculous spondylodiscitis: epidemiology, clinical features, treatment, and outcome. Eur Rev Med Pharmacol Sci 16(Suppl 2):58-72

89. Galhotra RD, Jain T, Sandhu P, Galhotra V (2015) Utility of magnetic resonance imaging in the differential diagnosis of tubercular and pyogenic spondylodiscitis. J Nat Sci Biol Med 6:388-393

90. Yusof MI, Hassan E, Rahmat N, Yunus R (2009) Spinal tuberculosis: the association between pedicle involvement and anterior column damage and kyphotic deformity. Spine (Phila Pa 1976) 34(7):713-717

91. Ozaksoy D, Yücesoy K, Yücesoy M et al (2001) Brucellar spondylitis: MRI findings. Eur. Spine 10:529-533

92. Cappabianca S, Scuotto A, Pecori B et al (1998) The recrudescence of spondylodiscitis due to migratory flows. The role of magnetic resonance as a method of first instance in diagnosis and follow-up. Radiol Med 95:551-556

93. Liu X, Li H, Jin C et al (2018) Differentiation between brucellar and tuberculous spondylodiscitis in the acute and subacute stages by MRI: a retrospective observational study. Acad Radiol 25(9):1183-1189

94. Panta OB, Pathak YR, Karki DB (2018) Magnetic resonance imaging findings in spondylodiscitis. J Nepal Health Res Counc 15(3):217-221

95. Frel M, Białecki J, Wieczorek J, Paluch Ł, Dąbrowska-Thing A, Walecki J (2017) Magnetic resonance imaging in differentatial diagnosis of pyogenic spondylodiscitis and tuberculous spondylodiscitis. Pol J Radiol 82:71-87

96. Berbari EF, Kanj SS, Kowalski TJ et al (2015) 2015 Infectious diseases society of America (IDSA) clinical practice guidelines for the diagnosis and treatment of native vertebral osteomyelitis in adults. Clin Infect Dis 61(6):e26-46

Publisher's Note Springer Nature remains neutral with regard to jurisdictional claims in published maps and institutional affiliations. 